D. Revista Humanismo

NO y Sociedad

\title{
Posibilidad de una psicología fenomenológica sobre las bases de una fenomenología de la persona en acción $\stackrel{\Perp}{*}$
}

\author{
Possibility of a phenomenological psychology based on a phenomenology of the person in action
}

El presente escrito es resultado de investigación de la tesis de Maestría en Filosofía que titula La Antropología filosófica personalista de Karol Wojtyla y la defensa de la dignidad humana.

Andrés Felipe López López ${ }^{1 \star}$, (c) Magíster.

${ }^{1}$ Miembro de la Asociación Española de Personalismo. Filósofo y candidato a Magíster en Filosofía de la Universidad Pontificia Bolivariana de Medellín. Estudiante investigador del grupo "Epimeleia" de la misma Universidad. Línea de investigación: Antropología, Ética y Sociedad. Líder del Grupo de Estudios e Investigaciones Educativas y Pedagógicas G.E.I.E.P. Profesor de la Universidad de San Buenaventura y coordinador de investigación de la Facultad de Educación de la Corporación Universitaria Uniminuto.

(Recibido: 8 de octubre de 2013; aceptado: 19 de noviembre de 2013).

\section{Resumen}

La formulación de una Antropología filosófica fundada en una Fenomenología de la persona se presenta aquí como el principio de validez de una psicología fenomenológica que garantiza el estudio de los fenómenos psíquicos con una nueva actitud: la actitud fenomenológica como reducción fenomenológica, que aplicada a la investigación y la intervención del psicólogo en el contexto clínico asegura que el ser humano sea visto en su singularidad especial y no con teorías que determinan que el hombre-sujeto ya está dado como una realidad estática. La idea del presente escrito es recuperar la existencia del hombre como devenir; la persona es sujeto de sus acciones y por ellas se llega al eidos de la unidad sustancial psico-física que es.

Palabras clave: acción, fenomenología, persona, psicología, reducción fenomenológica.

\section{Abstract.}

The formulation of a philosophical anthropology founded on a phenomenology of the person is presented here as the principle of validity for a phenomenological psychology. This psychology guarantees the analysis of psychic phenomena under a new attitude: the phenomenological attitude as a phenomenological reduction. When applied to research

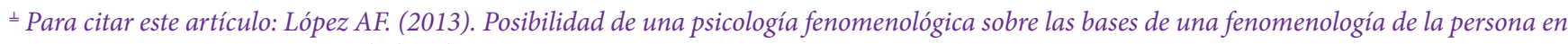
acción. Rev Humanismo y Sociedad. Volumen 1: 120-132

* Autor para correspondencia: Andrés Felipe López López. Corporación Universitaria Uniminuto. Km. 0 Autopista Medellín-Bogotá. Bello. Oficina Centro de Investigaciones, piso 4. E-mail: pipelopezlopez@hotmail.com.
}

Revista. Humanismo.Soc. 2013; Volumen 1: 120-132. 
and to the psychologist intervention in the clinical setting, this reduction ensures human be considered in its special uniqueness and not through theories that determine the human subject as a static reality. The idea of this paper is to recover human existence as becoming: the person is subject of his own actions and is through them that the eidos of human substantial psycho- physic unity can be reached.

Key words: action, phenomenology, person, psychology, phenomenological reduction.

\section{Introducción}

En su esencia el acto revela de modo inmediato un eidos sobre el que se sostiene la misma esencia del acto: la persona; el acto revela la totalidad, originalidad, y unicidad de todo ser humano (Wojtyla, 2005, pág. 114). La tesis central argumentada por Wojtyla en su investigación en Persona y acción (2011) es que "el acto es lo que revela más profundamente el ser humano como un 'yo' y con más certeza atestigua su carácter de persona" (2005, pág. 113); este artículo, dentro los límites mismos de la tipológica de texto que es, formula la Antropología filosófica de Wojtyla como Fenomenología de la persona y esta a su vez como un elemento de posibilidad para fundar una psicología fenomenológica. Esto no quiere decir que no se reconozca el influjo del tomismo en el pensamiento del autor (y esa influencia es evidente en la extensión de su pensamiento) pero si advierte que el enfoque dado es descriptivo respecto de la aprehensión de la acción como momento particular de la experiencia del hombre. El propósito es, siguiendo a Husserl en ello mediante la reducción fenomenológica en su sentido trascendental, dar luces acerca de la posibilidad de una psicología reformada cuyo tema es la subjetividad, en la que el Psicólogo funda su intervención clínica sobre una actitud que asegure la percepción del otro en su pureza.

\section{Sobre el método}

El presente escrito que deriva de una investigación más amplia sobre la Antropología filosófica de Karol Wojtyla, siguió la misma forma de composición argumentativa en el grueso de esa indagación mencionada; primero, el método demostrativo según como se entiende de Hegel en la Fenomenología del espíritu y de Aristóteles en Analytica posteriora que consiste en la demostración de una hipótesis, o en la demostración de la verdad de un axioma; segundo, se siguió la lógica expositiva entendida como la exposición de razones fundamentadas en autores que han pensado el tema en cuestión, y desde esas razones mostrar el ancho del problema; en este sentido de lo propositivo y proposicional se advierte que se ha usado lo que podemos llamar fluctuación estructural, que consiste en ir de las premisas a la conclusión por un lado y de la conclusión y la primera premisa a la segunda premisa, esto con la intención de explicar mejor el hecho descrito o conseguido en la conclusión. También, y más importante, todo lo que sigue está construido sobre la actitud fenomenológica (trascendental) que es un cambio radical y entero de forma de vida que sobrepasa por completo toda experiencia vital anterior, porque como análisis intencional es la experiencia que explica la experiencia misma en el sentido de aclarar el genuino sentido de la inmanencia por medio del giro de lo meramente doctrinal a lo trascendental como revisión de la experiencia interna.

\section{Fenomenología de la persona en acción: referencias cruzadas}

El doctor Roberto Walton en su artículo "Reducción fenomenológica y figuras de la excedencia” para la publicación Tópicos en el 2008, afirma que el tema central de la Fenomenología de Edmund Husserl es la correlación entre lo que aparece y su aparecer. Michel Henry lo expresa en otros términos y dice que el centro de la fenomenología es la esencia de la manifestación: el fundamento de lo aparecido, el fondo de lo que aparece. Según Michel Henry, en su texto La esencia de la manifestación (1963), la pregunta fenomenológica como ciencia de los fenómenos está ordenada no solamente por el mero aparecer de los objetos, sino por la esencia del aparecer: cómo aparece lo que aparece. La persona en la Antropología filosófica de Karol Wojtyla, abordada en este trabajo, aparece en 
el cuerpo con el que actúa. El aparecer de la persona se da en el cuerpo y de este su forma de manifestación es la acción; en estos términos el cuerpo es carne fenoménica y la acción manifestación de la unidad sustancial del hombre. Cuando el hombre actúa no se está expresando solamente un movimiento corporal y mecánico, sino la unidad psico-física y espiritual que él encarna o fenomeniza: en la acción no hay separación alguna entre movimiento corporal y experiencia interna, de esta manera la persona está colocada en la acción; por ella, gracias al saber primordial de que existo en un cuerpo me encuentro "Yo" autoafectado de manera doble, en la medida en la estoy vivo y soy, y en la medida en la que el otro me reconoce y experimenta. En la acción, la persona se trasciende a sí misma, porque en ella está presente el todo de mi ser personal y al mismo tiempo más del contenido del propio ser: a esto se refiere Wojtyla cuando usa la noción de "transfenoménico" en dirección a explicar que en el cuerpo y en la acción la persona estalla en fenómeno, debido en parte a que en los actos "Yo" me autoexperimento: la persona no solo está dentro de la acción sino que ella misma se percata de sí en la acción.

Heinrich Rombach distingue tres modos de la fenomenología; uno trascendental, uno hermenéutico y uno estructural: cosa, texto e imagen, respectivamente; siendo a la cosa la percepción, al texto la teoría y a la imagen el nexo (Walton, 2008). La Antropología filosófica debería identificarse con el primer modo: una Fenomenología trascendental de la reducción trascendental en la que el "que" del objeto-fin del conocimiento fenomenológico, se convierte en un "quien" no reducible a cosa, ya que la persona estalla a mi percepción como valor; "Yo" intuyo, comprendo y vivo que la persona es valor, es digna.

La Idea de "Persona y acción" y su respectiva correlación presentada por Karol Wojtyla en la obra que lleva el mismo nombre es fruto de investigaciones anteriores, concretamente la referente a la Ética Scheleriana; Max Scheler continua el camino de la Fenomenología de Edmund Husserl haciendo su propia aplicación del lema "volver a las cosas mismas" siendo la Ética la cosa en sí y lo objetivo de los valores materiales de la Ética (y la moral) su objeto de conocimiento. Esta intención de Scheler tiene en el fondo el problema que nace de la pregunta por el sujeto, por la persona, que es a lo que Wojtyla regresa: el ser humano en cuanto sujeto, y es en esa medida que su punto de observación en términos fenomenológicos puros son las articulaciones de la actividad humana para concluir en la descripción de la estructura óntica del ser que es específicamente humano y que actúa junto con otros en el mundo de la vida.

Según Anna-Teresa Tymieniecka, quien prepara la publicación de Persona y acción e introduce la obra: “(...) ni el análisis genético trascendental, que se centra en la génesis de la conciencia humana constitutiva de un mundo de vida, ni el análisis eidético de las estructuras de la objetividad en cuanto tal, han abordado directamente la acción humana" (Wojtyla, 1982, XIV): no se había abordado la acción humana en cuanto "cosa en sí" como estado de las cosas mismas. Persona y acción (Wojtyla, 1982) es un estudio eminentemente antropológico no ético, dice también Tymieniecka.

El axioma que sostiene esa Antropología consiste en la afirmación de que el conocimiento de la persona se basa en la experiencia del hombre, una experiencia que a su vez es intelectual porque reducir la totalidad de esa experiencia a los contenidos resultados de la sola percepción sensorial sería causa de grandes contradicciones y vacíos. En esta experiencia el hombre se ve enfrentado consigo mismo de una manera continua porque el hombre incluso cuando duerme sigue en su propia compañía; incluso cuando duerme, como cualquier otro acto consciente o mecánico, el hombre es totalidad dinámica observable en la experiencia fenomenológica, que es superior, por su significado total e integrador, a la experiencia netamente sensible. La acción que es un dato objetivo que presupone una persona captura un momento particular de la experiencia del hombre. En otras palabras, lo dado como dato es, que el hombre actúa; es como si por medio de la acción se focalizara la persona porque la revela en un momento específico; dice Wojtyla en ese mismo marco que "la acción nos ofrece el mejor acceso para penetrar en la esencia intrínseca de la persona y nos permite conseguir el mayor grado posible de conocimiento de la persona. Experimentamos al hombre en cuanto persona, y estamos convencidos de ello porque realiza acciones" (1982, pág. 13).

Por otro lado, si la acción presupone una persona y toda acción tiene un agente, este hecho corrobora de manera objetiva el significado y el sentido necesario de 
la moral dado que como dice Wojtyla, si bien el hombre se encuentra en el origen y los efectos de la valores morales, las acciones son por tanto el reflejo más puro de la persona: a consecuencia de sus acciones buenas o malas el hombre me es dado respectivamente como bueno o malo.

Metodológicamente Wojtyla (2011) explica la característica particular de tipo matemática que posee su investigación antropológica, distinta del procedimiento de la suspensión o poner entre paréntesis del método de Edmund Husserl, y sin embargo no distinta en su espíritu científico, o al menos muy cerca, de superar la permanencia en la "actitud natural" por la actitud fenomenológica que consiste en aniquilar la tiniebla de la experiencia objetivista e ingenua del mundo donde las cosas son sin haber tematizado la experiencia donde verdadera y genuinamente son, poniendo por tema la constitución del mundo en mí que soy conciencia; la colocación entre paréntesis tiene la siguiente forma explicada por Husserl en lo que él llamo "meditación fenomenológica fundamental" primer capítulo de Ideas relativas a una fenomenología pura: "ponemos fuera de juego la tesis general inherente a la esencia de la actitud natural" (1993, pág. 73). Esa tesis junto con su actitud es "puesta fuera de juego", "si así lo hago, como soy plenamente libre de hacerlo, no por ello niego 'este mundo', como si yo fuera un sofista, ni dudo de su existencia, como si yo fuera un escéptico sino que practico la reducción 'fenomenológica”' (1993, pág. 73). El ego fenomenológico intencional suspende y pone fuera de juego la tesis del mundo de la actitud natural porque en ella "no puede verse justamente nada más que el mundo natural” (Husserl, 1993, pág. 76) en el que no conquisto regiones del ser antes desconocidas, entendiendo ser en esta lógica como "vivencias puras" en el ámbito de mis cogitationes o "actos de conciencia". El punto de observación empírico de Wojtyla sobre la persona es la evidencia personal que remonta a una "esencia propia, intuitivamente aprehensible, un 'contenido' susceptible de que se lo contemple por sí en lo que tiene de peculiar” (Husserl, 1993, pág. 78).

Wojtyla en sus meditaciones sobre la persona en acción pone fuera del paréntesis la Ética en cuanto factor común de la relación que hay entre ésta y la antropología y como componente de la persona humana. Esta es una operación algebraica que consiste en destacar el factor común en todos los términos que componen un enunciado, una ecuación o una expresión, no abandonándolo por su aislamiento intencionado, sino suspendiéndolo temporalmente para que no se pierda o se distraiga su importancia en los otros términos, y estos a su vez no se vean confundidos en el contenido del factor común: "se trata de excluir los problemas esencialmente éticos para dar mayor importancia a los antropológicos" (Wojtyla, 1982, pág. 16. 293). En conformidad a la racionalidad matemática que se encuentra implícita en el método fenomenológico en sí mismo y en el método de Wojtyla, la expresión tendría la siguiente forma:

Sean las siguientes variables infinitas, determinadas y por determinar los componentes estructurales del hombre, siendo la Ética representada en X:

$\mathrm{X} Z$ : cuerpo (corporalidad)

$\mathrm{X}$ A: instinto

$\mathrm{X} Y$ : impulso afectivo

$\mathrm{X}$ B: memoria

$\mathrm{X} \mathrm{C:} \mathrm{inteligencia}$

X L: espíritu

$\mathrm{X}$ D: conciencia

X S: intuición

$\mathrm{X}$ T: intencionalidad

X R: sustancia divina

$\mathrm{X}$ U: trascendencia

$\ldots \infty$

Considerando como conjunto infinito todas las posibles componentes estructurales del hombre

Donde Hombre $\mathrm{H}=\mathrm{X} \mathrm{Z}+\mathrm{X} \mathrm{A}+\mathrm{X} \mathrm{Y}+\mathrm{X} \mathrm{B}+\ldots \infty$ $\mathrm{H}=\mathrm{X}(\mathrm{Z}+\mathrm{A}+\mathrm{Y}+\mathrm{B}+\ldots \infty)$

Sea F la aplicación Unidad Psico-Física: $\mathrm{H}$------> X $\{\mathrm{Z}$ $+\mathrm{A}+\mathrm{Y}+\mathrm{B}+\ldots \infty)$

Según como se presenta la Fenomenología de la persona y la Antropología filosófica personalista de Wojtyla, la acción como momento privilegiado, como "cosa" en un "quien" que es persona lleva a la afirmación de que por la acción se atrapa toda la inmanencia o interioridad del sujeto. Esa experiencia es analítica en cuanto a argumentos y reductiva en cuanto a comprensión, teniendo en cuenta, en aras de aclararse en el lenguaje, que reductiva no denota reducción como disminución, denota en sentido fenomenológico, dilucidación, meditación, explicitación, y bajo esa referencia Wojtyla hace reducción a la acción en sentido fenomenológico 
para dar luces descriptivas sobre la estructura óntica de la persona diciendo que la acción en cuanto fenómeno humano significa "actuar conscientemente" (Wojtyla, 1982, pág. 34, 37). En la conciencia a la consideración del pensador del que tratamos, todo se refleja y en ella está contenido todo el hombre: la conciencia es espejo egóico y espejo del otro; sabiéndose espejo la conciencia, el ego como subjetivamente autoconstituido, es dado como objeto para sí porque la conciencia es el lugar donde la persona experiencia su propia subjetividad. Por la conciencia y en ella, el hombre se descubre hacia dentro y se descubre específico, singular y único; es decir que la experiencia de si y la afección de mi existencia no son solamente materiales o corporales, sino que son espirituales en la medida en que en la conciencia se forma la experiencia humana. De la conciencia también resulta el predicado o atributo rationale propio de la concepción aristotélica y boeciana: rationalis naturae individua substantia. Según Wojtyla "(...) de hecho, la experiencia que el hombre tiene de sí mismo y de todo aquello que le constituye, de todo su 'mundo', ocurre necesariamente dentro de un marco de referencia racional, pues así es la naturaleza de la conciencia, y determina la naturaleza de la experiencia y, por así decirlo, su nivel en el hombre" (1982,pág. 59). Por la conciencia y su función de reflejo, opina Wojtyla, conocemos el bien y el mal de manera objetiva en cada una de las acciones puesto que la acción fenomeniza junto con la persona, el bien o el mal hecho. A la conciencia se atribuye entonces en la Fenomenología de la persona y la Antropología filosófica wojtyliana el autoconocimiento como autoconciencia y la posesión de sí mismo que sin la conciencia de sí es imposible porque el núcleo de la conciencia soy yo mismo, es el ego.

Aclaremos, como hace Wojtyla, la diferencia referencial entre subjetividad y subjetivismo; esta última es una actitud que conduce a la consideración de la verdad como dependiente de la constitución del sujeto que conoce: lo que es verdad para un sujeto puede no serlo para otro. El subjetivismo reduce toda verdad a la individualidad psíquica de un sujeto particular. La subjetividad por otro lado es un elemento del realismo ontológico en el estudio de la persona porque refiere a la conciencia en tanto que ella es la que posibilita que el hombre se experimente como sujeto, como agente de sus acciones: esto es la eficacia de la conciencia que me revela en su unidad al hombre como sujeto agente.

\section{La eficacia}

La eficacia es una experiencia del hombre en acción. La eficacia aparece en la autovivencia del "yo actúo" porque experimento mi dinamismo como acción y como lo que me ocurre. Es de resaltar que en la Antropología filosófica de Wojtyla no es lo mismo acto del hombre y acción humana, la última corresponde propiamente al hombre y su actividad pensada mientras que la primera a "algo ocurre en el hombre" en la que no necesariamente tengo la experiencia de sí mismo como agente. La eficacia conduce al orden objetivo del ser y de la existencia, a la naturaleza existencial. En la acción el hombre es sujeto causal, en el "algo ocurre en el hombre" soy sujeto pasivo. Lo que ocurre en el hombre no puede definirse como acción, sino como "activación" que aunque no contiene todo el sistema del dinamismo humano, si se deriva de él. La acción en términos fenomenológicos lleva a la consecución del eidos hombre como agente y creador. Aquí la moralidad, como se sugirió ya, encuentra su significado verdadero puesto que cuando el hombre lleva a cabo la acción se experimenta a sí mismo como agente y no como sujeto pasivo en el que ocurren cosas mecánicas del orden natural.

Cuando el hombre concreto existe, la individua substantia de Boecio, existe colocado en su actividad consciente y biofísica, en su dinamismo que es único, individual. Aquí el concepto de persona resalta: esta noción es superior a la de individuo de naturaleza racional (persona est rationalis naturae individua substantia) también de Boecio, porque es más significativa al referirse a "alguien", es decir a un hombre o todos los hombres reales y únicos en su especial irrepetibilidad. La existencia de cada ser humano no es solamente individual en sentido singular, sino que es personal. En este punto advierte Wojtyla (1982), es importante decir que una cosa es la referencia a la naturaleza humana como esencia, como aspecto inherente único a lo humano y otra la referencia a la persona. La naturaleza humana es el nacimiento, en sentido biológico y en sentido explicativo del dinamismo. La naturaleza denota el comienzo de la existencia en el mundo de la materia, existencia que se fenomeniza en el operari o funcionamiento. Siguiendo el concepto de "reducción fenomenológica" que refiere a la operación más total y centrada en la esencia de un objeto, la naturaleza se manifiesta o fenomeniza 
como lo que ocurre en el hombre: en el momento de la activación se manifiesta la naturaleza del hombre. La eficacia por su lado está contenida en las acciones porque ellas muestran un ego especial de la acción. La existencia humana es la síntesis de actuar y ocurrir dado en el hombre: síntesis de acciones y activaciones, de eficacia y naturaleza respectivamente. La naturaleza como activación y la acción como eficacia, aunque son momentos distintos uno del otro, son momentos de la unidad e identidad del ego puesto que pertenecen a la unidad sistémica que es el hombre. La humanidad es la base de la persona cuyos constitutivos son ser y actuar, por eso se dice con verdad que el ser humano posee "personalidad" y ésta entendida como la afirmación del hombre como persona, como ser autónomo subjetivo, autoconsciente. Sin embargo en la unidad que es, humanidad y personalidad son términos con significados distintos. Humanidad es la naturaleza, lo que personalidad es a dinamización.

La acepción metafísica a naturaleza como esencia de un ser es ampliada por una concepción fenomenológica de la misma, como esencia de un ser humano dinámico: solo actúa quien existe. En la persona en acción se integra la naturaleza humana, como integración del dinamismo propio del hombre. Actuar y ocurrir son "humanos" porque provienen de la humanidad de la persona. El hombre "posee" personalidad porque es persona, porque actúa conscientemente, porque sus acciones tienen una auto-vivencia y conciencia particular y especial. Por un lado la humanidad es el trasfondo de la persona y la personalidad, es el trasfondo de la acción y por el otro, la naturaleza es la base causal de la estructura óntica en la que esta soportada la potencialidad del hombre-sujeto.

\section{La conciencia y el cuerpo}

"Elhombre tiene conciencia de su cuerpo, pero en cuanto que tiene su vida específica. El tener conocimiento de su cuerpo lleva, indirectamente, a tener conocimiento del organismo" (Wojtyla, 1982, pág. 107). De los hechos que conforman su dinamismo biológico el hombre no tiene conocimiento particular, empero la experiencia del cuerpo y la conciencia del cuerpo casi en su totalidad es posible gracias a las sensaciones. El hombre como autor de acciones es sujeto dinámico pero lo es también por todo lo que ocurre en él. El cuerpo es con la conciencia y la personalidad, también un elemento de la identidad univoca de cada hombre: el sujeto es único e idéntico a sí mismo, es un alguien irrepetible también porque posee cuerpo o porque él tiene cuerpo que es de su lado el lugar real de la unidad psico-física y de la unidad dinámica; el cuerpo es un elemento fundamental de cualquier Antropología: "Un análisis del cuerpo humano, de la persona en acción, que estuviera basado únicamente en la conciencia, estaría condenado desde el primer momento a resultar inadecuado." (Wojtyla, 1980, pág. 109). Dice Husserl respecto de la Psicología como ciencia, referente al carácter categórico del cuerpo para el estudio del hombre siguiendo la línea que lleva este artículo que:

El orden psíquico no es un mundo en sí; esta dado como yo y como vivencia del yo (en un sentido por lo demás muy diferente), y como tal se presenta en la experiencia, ligado a ciertas cosas físicas llamadas cuerpos. También esto es un dato previo evidente. Por lo tanto, la tarea de la Psicología es estudiar científicamentelo psíquico en el complejo psicofísico de la naturaleza en que se da, determinarlo de un modo objetivamente válido y descubrir las leyes según las que se forma y se transforma, aparece y desaparece. Toda determinación psicológica es eo ipso psicofísica, es decir, en el sentido más alto de la palabra, ella tiene siempre un sentido físico que jamás abandona. Aun cuando la psicología -ciencia de la experiencia- se propone exclusivamente la determinación de los puros acontecimientos de la conciencia y no de los nexos psico-físicos en el sentido habitual y más estrecho del término, esos acontecimientos son pensados sin embargo como pertenecientes a la naturaleza, es decir, a conciencia de hombres y de animales y se comprende de un modo evidente que, por su parte, estas conciencias están ligadas a cuerpos humanos y animales. La desconexión de la relación con la naturaleza privaría a lo psíquico del carácter de hecho natural determinable objetiva y temporalmente, en suma, de su carácter de hecho psicológico. Por lo tanto, recordemos lo siguiente: todo juicio psicológico contiene en sí, explícitamente o no, la posición existencial de la naturaleza física (1969, pág. 55).

El espíritu, la conciencia o si se quiere la esfera de lo psíquico está basada en la physis humana: "toda vida psíquica individual-humana está fundada en la corporeidad (...)” (Husserl, 1969, pág. 137). La 
conciencia estudiada como conciencia en sentido abstracto, sin estar dada en la corporeidad, y esta sin su conexión y unidad con la primera, es una pura especulación porque:

Hombres y animales no son solamente cuerpos, pero en la orientación de la mirada hacia el mundo circundante ellos aparecen como algo existente de un modo corpóreo, por consiguiente, como realidades dispuestas en la espacio-temporalidad universal (...) El método científico natural tiene que descubrir también los secretos del espíritu. El espíritu es real, se halla objetivamente en el mundo y como tal fundado en lo corpóreo (Husserl, 1969, pág. 163).

Las consideraciones del ser humano como ser corpóreo llevan directamente a otro análisis, el del devenir, "llegar a la existencia equivale a devenir" (Wojtyla, 1982, pág. 115). El dinamismo humano revela que el devenir del hombre en la existencia es un dato real. El organismo humano como sistema viene ya determinado en su propio desarrollo, pero la esfera psíquica aun cuando está fundada en ese sistema, es la persona humana quien la determina en su perfeccionamiento.

\section{La autodeterminación y la trascendencia}

La voluntad y la libertad interior del hombre se fenomenizan y se experiencian ${ }^{2}$ en otra dimensión: la libertad es un dato objetivo de que la voluntad existe de un modo real; la persona es la que se manifiesta en la voluntad, en la capacidad de realizar acciones como posesión de la libertad. Solo es "persona" quien tiene posesión de sí mismo y esa posesión es y debe ser exclusiva e individual. El ego de la persona se encuentra referenciado en la autodeterminación de ser "alguien", no "algo" que es la categoría en la que existen todos los demás seres; la persona es alguien porque es sujeto de sus estructuras y dinamismos: la persona objetiva su propio ego gracias a la autodeterminación. La persona en la acción trasciende; para una Filosofía de la persona y una psicología fenomenológica (existencial) ${ }^{3}$ fundada en una Fenomenología de la persona, así lo dice Wojtyla:

El problema está en determinar cómo el acto humano, la acción, es un acto real de la persona, pues en él no solo se actualiza una naturaleza racional individual, sino que también se realiza un acto -tal como demuestra la experiencia-, cuyo agente es la persona individual y única. La realización de una acción es, al mismo tiempo, la realización de la persona (1982, pág. 131).

Y sigue más adelante:

Toda acción es una manifestación exterior de la persona, aun cuando se realiza de forma totalmente interior, y merezca por ello mismo la calificación de "interior" (actus internus) (...) La persona no solo está objetivada en cada una de sus acciones, sino que también se manifiesta a sí misma exteriormente, aun cuando sus acciones, desde el punto de vista del criterio de perceptibilidad, tengan todos los rasgos de la interioridad (1982, pág. 134).

La persona se muestra como la estructura misma y real de la autodeterminación, como autogobierno y autoposesión; el hombre es persona porque es consciente y se autodetermina, distinto a los otros seres de la naturaleza que son meros individuos pero no egos constituidos. Decir que la persona es libre es afirmar en ella su trascendencia y su dependencia inmanente; esa libertad es una capacidad que viene dada por la voluntad como fuerza, porque la voluntad es la raíz de la acción y como voluntad ésta se mueve hacia un objeto que se le presenta, querer por ejemplo significa tender hacia un valor que en sí mismo es un fin; la voluntad por tanto esta siempre dispuesta a salir hacia el bien, por esto mismo la persona es "El" centro concreto de la libertad no como independiente de los valores y objetos, sino como libertad para los valores y objetos; tomar una decisión, por ejemplo, es un dato que evidencia que el hombre responde con la libertad a unos valores que se le presentan, unos valores que son objetivos. Esto es ascendencia de la persona sobre

\footnotetext{
${ }^{2}$ La expresión es tomada en su uso según como la entiende el autor de este artículo del doctor Roberto Walton en su artículo citado más arriba.

${ }^{3}$ Entiéndase por "existencial" no una Filosofía de la vida y de la existencia irracional y acientífica; el sentido del término aquí es el referente a la valoración radical de la particularidad de cada persona.
}

Revista. Humanismo.Soc. 2013; Volumen 1: 120-132. 
su propio dinamismo, esto es la trascendencia: una rendición de la voluntad ante la verdad. "La elección así como la toma de decisiones -cada una a su propia manera-, se realizan haciendo referencia a la verdad del objeto reconocido como un bien positivo" (Wojtyla, 1982, pág. 167). Tanto en tomar decisiones como en elegir se presupone la existencia objetiva de la verdad como experiencia cognoscitiva de la misma en un objeto que aparece como bien; ese aparecer es su verdad elegida o decidida como verdad axiológica, como valor, distinta a la verdad ontológica y lógica. Conocer en sentido de verdad axiológica está relacionado con el querer, con la intencionalidad: "Percibir la verdad es lo mismo que presentar un objeto a la persona-sujeto a través de una de sus propiedades intrínsecas" (Wojtyla, 1982, pág. 168). Nótese que dice "presentar" como darse del conocimiento humano en la experiencia.

El hombre se percibe o se experiencia como el agente del pensamiento y del conocimiento: ambos se dan en forma de juicios, pensamos por medio de juicios y los expresamos en frases; incluso en el sentido de la verdad axiológica, siempre que una persona toma una decisión o una elección tuvo antes que hacer un juicio de valor sobre el objeto al que se dirige y que es además objeto de su libertad. Los juicios de valor son aquellos que plantean un determinado valor, sin embargo al valor en sí no se accede de forma exclusiva por medio de un ejercicio intelectual, sino que los juicios de valor se encuentran en el pensamiento de antemano, los valores se intuyen; la intuición es un recuperar la verdad y permanecer en su esplendor, de aquí que la trascendencia de la persona en la acción está relacionada a la aspiración de decidir y elegir el bien como verdad intuida; la acciones humanas no son realidades invisibles en el tiempo, sino que tienen su prolongación en la misma persona y en los otros como valor moral; la persona es alguien, y aparece como alguien porque actúa y se actualiza a sí misma en su acción mientras se realiza; es alguien, no algo, porque se autogobierna y se autoposee; estas ideas demuestran que la persona y la acción no son realidades separadas, sino que una y otra son parte de una única realidad: esta es una interpretación filosófica y fenomenológica pura de la persona en acción, de la persona que actúa en cuanto resultado interno de su eficacia personal.

Toda acción es una evidencia de la realización personal, pero esa realización solo se da en un "si" en sentido axiológico cuando las acciones están dirigidas hacia el bien: el mal en sentido axiológico es la no realización de la persona. La realización y la trascendencia de la persona en acción son una certidumbre que muestra al hombre-sujeto como un ser potencial. Por ejemplo la persona no es buena o mala, sino que a consecuencia de su libertad, la persona en sus acciones se da de manera objetiva como buena o mala, y así mismo la libertad aparece como un hecho real rendida a la verdad del valor: para una defensa de la dignidad de la persona humana, esa verdad es el otro como valor. La percepción de la verdad es también una aspiración a un fin que es objeto y valor: la razón ante la verdad como valor se rinde ante su poder normativo, esto es un dato de la realidad espiritual de la persona.

\section{Posibilidad de una psicología fenomenológica con base en una fenomenología de la persona en acción}

A partir de una Antropología Filosófica personalista que valora la singularidad especial de la persona y una Fenomenología de la persona es posible plantear una Psicología fenomenológica cuyo tema de investigación central es el sentido de la experiencia del ser humano, con el objeto de no hacer juicios inadecuados resultado de una idea equivocada del hombre. Una Psicología fenomenológica va a la individualidad de cada persona y no la encierra en conceptos y teorías estáticas y no pone en la persona, también cuando es paciente, los juicios a priori venidos de la teoría psicológica: esta última no es una actitud fenomenológica; en actitud fenomenológica no se escapan los elementos particulares de la experiencia de cada persona. Para Husserl, en la Introducción a Ideas Relativas a una Fenomenología pura (1993), la psicología es la ciencia de los fenómenos psíquicos, y la fenomenología a su vez la ciencia de todos los fenómenos en todas sus significaciones posibles pero eliminando los vicios e imposiciones que han desorientado la razón y que limitan el conocimiento y que no dejan ver el fenómeno en su puro aparecer. "La Psicología es una ciencia empírica” (Husserl, 1993, pág. 9), en el sentido de que es una ciencia de hechos y de realidades, ya que los fenómenos que estudia son sucesos reales porque tienen en el ser humano una existencial real. Empero la Fenomenología es una ciencia de esencias y no de hechos, fija un eidos de un objeto que puso por tema, 
pero no fija hechos. Si la Psicología como ciencia de fenómenos psíquicos tiene por método, el método fenomenológico, no solo fijará hechos sino que llegará a las esencias puras de su objeto real: la psique del ser humano. La Fenomenología en cuanto ciencia también de la conciencia no es psicología, y la psicología no es netamente una Fenomenología, sin embargo una psicología fenomenológica no es una ciencia de la naturaleza en la que las cosas se presuponen como existentes con independencia de la subjetividad, como parte de un mundo natural en el que las cosas son evidentes; la ciencia de la naturaleza pone por temas las cosas pero no el reino en el que se dan, no los elementos causales en su unidad: como es el caso del ser humano, cuya estructura es una unidad psico-física, conocer eidéticamente su esencia es encontrar el "que" de un "quien" especial.

Comprender fenomenológicamente la realidad psíquica del ser humano es rescatarlo en su individualidad. Ese rescate se hace por medio de la experiencia del hombre objetivada en acciones según como hemos defendido con la Antropología filosófica de Wojtyla. El fondo epistemológico en el que se sostienen las acciones y la subjetividad es la experiencia. La experiencia del hombre como vivencia de lo por él vivenciado es un dato de su modo de intencionar el mundo, el horizonte y su realidad particular: he aquí el camino del Psicólogo en el conocimiento de la persona.

James Bugental en "The Five Basic Postulates of Humanistic Psychology" adaptado por Tom Greening (1964) dice que existen unos elementos primordiales que toda Psicología debe tener en cuenta como criterio de validez científica y como ciencia humana; Bugental los postula así: el primero refiere a que el ser humano es mucho más que la suma de sus partes; el segundo dice que la existencia de los seres humanos se da en un contexto específicamente humano; el tercero, que siendo libres los hombres estos eligen, y porque eligen la responsabilidad los caracteriza; el cuarto: los seres humanos son intencionales y el quinto, muy en relación con este último, dice que los seres humanos son conscientes, en tanto que el ser humano sabe que sabe. Estos postulados junto a los de la Fenomenología de la persona son un principio de articulación de la Psicología fenomenológica que se abre a la experiencia de cada persona y que no la considera como objeto o cosa, sino como hombre-sujeto especial e irrepetible; en el hombre concreto, en la persona en acción las experiencias humanas son particulares porque particular es la intencionalidad, en el sentido de que no hay dos intencionalidades iguales; cada persona aporta y participa en la vida junto con otros su especial vivencia de la cosas: el sufrimiento por ejemplo, aunque sea causado por el mismo agente o cosa, no lo sufren igual dos personas distintas.

Una psicología fenomenológica se formula como contraposición a algunas teorías clásicas de la Psicología que separan al hombre de su realidad, y por tanto de la vivencia de esa realidad particular como totalidad de la experiencia particular de un ser humano concreto. A priori el hombre no se conoce, porque el hombre, como se ha descrito en la Antropología filosófica de Wojtyla, está en devenir. El ser humano no se entiende como una naturaleza predeterminada, porque si bien hace parte del mundo de la vida, el hombre crea y transforma el mundo de la vida con la acción. Es aquí, a esta tesis de la naturaleza predeterminada a la que hay practicar la epoché y sacarla fuera de juego, para que con ella queden suspendidos lo preconceptos y las construcciones teóricas que generalizan la vivencia del hombre ocultando a la vista analítica del antropólogo, del fenomenólogo [filósofo] o psicólogo, cómo experimenta el hombre su misma experiencia. En la teoría preconcebida de una persona concreta se diluye y se pierde su individualidad. Al respecto Medar Boss en "Existential Foundations of Medicine and Psychology" (1979, pág. 85) afirma que el ser humano debe ser contemplado en su propio e indiviso manifestarse, la pregunta desde la ciencia psicológica que vehicula la intervención del psicólogo entonces tendría la siguiente forma: ¿Cuál es la esencia del aparecer del hombre? o ¿Cuál es la forma de su manifestarse? ¿Cómo se me da el hombre, y en lo que se da, como se le ha dado al hombre su propia experiencia? El objeto de estudio nuclear de la Psicología fenomenológica es atender al ser humano desde el sentido y el significado de la experiencia particular, no como el psicólogo cree o piensa que debe ser la vivencia por la persona experienciada en su existencia concreta. Hasta aquí, no se debe entender que se niega la psicoterapia, al contrario se la pretende afinar como el abordaje de una persona bajo la pregunta: ¿Quién es este ser concreto que tengo ahí delante y tomo por tema? Es pasar del naturalismo a la realidad existencial: la forma de los fenómenos psíquicos en cada ser concreto, de 
modo que se complejiza la tarea y la intervención del psicólogo en un contexto social, pero se hace su tarea más real porque su punto de encuentro con el hombre es la historia de la persona.

Visto desde la psicología fenomenológica, el psicoanálisis tiene graves puntos de revisión. Rollo May otro defensor de una Psicología existencial dice que el Psicoanálisis al poner la causa de las acciones y conductas en el inconsciente quita el sentido de la responsabilidad de la vida humana, puesto que "Yo" no soy culpable de lo que hago, o en otras palabras otra dimensión dentro de mí que no puedo controlar es la que obra. Si aceptamos que las acciones y los comportamientos del ser humano son resultado causado del inconsciente, aceptamos también que el ser humano no es libre.

Freud argumentó que aunque el hombre posee voluntad la fuerza de ésta es inferior a la de los deseos del inconsciente que terminan determinando las acciones humanas ¿no será más bien que los pacientes neuróticos han sufrido un detrimento de su libertad, en tanto que se les ha privado de la posibilidad de la experiencia? En este sentido el sacar a la luz lo que se encuentra oculto, desvelar y hacer consciente, no se da en la forma psicoanalítica, sino que se da como una revisión de la intencionalidad presente sobre los hechos del pasado. ¿Cuál es la intencionalidad de la persona sobre su propio inconsciente? el inconsciente es posible solo porque la conciencia existe como un dato; el inconsciente incluso es una construcción del consciente porque intencionalmente el hombre oculta; su intencionalidad muta como no intencionalidad sobre lo vivido en el pasado; una no intencionalidad puede ser vista fenomenológicamente como intencionalidad del ocultamiento; ocultar es una acción, ocultar fenomeniza una experiencia interna: se pone como no intencionado lo vivido; ocultar o no aceptar es un estado psíquico, no un "no estado".

Una psicología fenomenológica está en orden a esclarecer la intencionalidad con la que el ser humano se relaciona con el pasado en el momento presente, para llevar a la persona como paciente, a considerar que el tiempo es una unidad existencial vivida $y$ continua. Un ejemplo: una mujer que ha sufrido una violación durante su niñez (6 años de edad) por un hombre en sentido masculino, evita vincularse a otra persona (hombre) para no revivir lo pasado, para evitar ser transgredida otra vez o bien se obsesiona con otra persona concreta como fuente de protección, o elimina a la figura masculina como especificidad afectiva. En los tres casos, la persona afectada no pone por tema el pasado y su hecho concreto, sino que lo esconde por medio de su intencionalidad yuxtapuesta, para no hacerse responsable de si frente al otro, o para no hacerse responsable incluso de su propia experiencia y pensar que el "problema" siempre está en los otros. No somos empujados, como decía Freud, por esa experiencia del pasado, sino que nosotros la empujamos fuera de nosotros mismos o a un lugar escondido de nosotros mismos, esta actitud es inauténtica. Sin embargo hay circunstancias de la vida en las que es inevitable volver a esa experiencia de sufrimiento sobre la que la intencionalidad es usada como no intencionalidad, porque no existe en quien se comporta así, una reconciliación con la vida misma ni se ha asumido el peso de la historia personal. No es que la persona no pueda entender lo ocurrido, sino que no quiere: el inconsciente es posible como concepto solo como conciencia, puesto que el inconsciente es una conciencia no asumida, es intencionalidad autoreprimida que necesitó de la intencionalidad para ser reprimida; lo que habita en el inconsciente es una "conciencia siempre de algo" oculta voluntariamente. Lo que no se hizo voluntariamente fue limitar las experiencias posteriores a la vivencia del hecho ocultado.

Nótese como Kirk Schneider en "Existential-integrative Psychotherapy" (2008) afirma que la intencionalidad puede orbitarse, en el proceso de afirmar o preservar un valor, en tres formas: [1] las tendencias dirigidas a la centración, [2] a la expansión, y [3] a la constricción del propio potencial. La primera, que es la que para una Psicología fenomenológica interesa, como centración, es la manera como el ser humano integra las dos siguiente formas: en otras palabras el ser humano aprende a ser sujeto de la experiencia y objeto de la misma.

En la intencionalidad se encuentra integrada toda la persona, es toda ella intencionalidad; el punto es discernir a partir de la evidencia qué es lo que la persona quiere lograr con la experiencia de revelar $\mathrm{u}$ ocultar, en el caso del ejemplo puesto aplicable a una multitud más de hechos: cuál es el sentido de la 
intencionalidad. Los deseos son indivisibles en tanto que hacen parte de un sistema unitario Psíco-físico que es la persona. Traduciendo el pensamiento de Rollo May en términos fenomenológicos puros en "Análisis y significado del movimiento existencial en psicología; y contribuciones de la psicoterapia existencial" (1977) dice que la persona como paciente, y la persona como momento de la intervención del psicólogo, necesita ser llevada a la experiencia de sí misma para fenomenizarse ante el Psicólogo clínico como eidos y poder dar interpretaciones o descripciones esenciales de su vivencia particular en función de su salud mental.

Para Husserl, la actitud con la que se mira la cosaobjeto de conocimiento y su relación con el objeto mismo, respectivamente conciencia y objeto, forman una sola experiencia vital. En un primer momento Husserl buscó las bases del conocimiento en lo dado, en el objeto fenomenizado, luego se fue percatando que esas bases se encuentran más profundas y en un polo distinto al objeto: el sujeto. Sujeto como conciencia ante la cual aparecen los fenómenos y estos son captados por actos esenciales de conciencia o actos intencionales. Lo objetos en la conciencia son esencias ideales. Este momento de volver al sujeto, se dice, se da a partir de su publicación de las Ideas Relativas a una Fenomenología Pura en 1913, desarrollándose la idea con más precisión por ejemplo en la publicación de Meditaciones Cartesianas (1965) en 1931 o el artículo La crisis de las ciencias europeas y la fenomenología trascendental en 1936. En esta última fase el fenómeno es interpretado como significado, como correlato intencional de los actos trascendentales.

Para Husserl el conocimiento es el resultado de la reducción fenomenológica: la conciencia pura; dice Husserl en las Meditaciones Cartesianas: "solo en la conciencia no está infectado el ser con la facticidad que constituye un impedimento para lo absoluto" (1965, pág. 45). En el ego trascendental es donde se da una experiencia trascendental, porque el ego trascendental constituye y contiene todo significado, en el ego trascendental está contenido el mundo de los fenómenos.

El ego es unificación de todos los actos intencionados: el mundo es el término inmanente de la intencionalidad porque se encuentra constituido en el ego trascendental que ha sido objeto de las respectivas reducciones en las que el sujeto cognoscente se ha volcado sobre sí mismo. No basta con dominar el método fenomenológico como técnica, ni pensar que se está en las cosas mismas, es necesario revisar la intencionalidad constantemente como un volver ya no sobre las cosas mismas, sino sobre mí como conciencia: esto es la reducción trascendental, un cambio de actitud única y verdaderamente filosófica y por tanto científica que es a su vez una actitud "antinatural" porque es una ruptura con el mundo, con la ingenuidad y con la aceptación del dogma. El darse de las cosas, incluyéndome, se constituye en la intencionalidad. La conciencia misma que es fuente de inteligibilidad no es una cosa o ente, ni un hecho ni un proceso en un ente, sino la subjetividad absoluta, en ella se contiene todo el hombre. En este sentido, una psicología fenomenológica por ejemplo, aclara la experiencia del otro en el sentido de cómo yo lo experimento, y la experiencia del otro (alter ego) sobre si junto con la que tiene de mí. El Yo como tema de la Psicología es el mismo Yo como ego trascendental de la fenomenología: la historia de mi vida estudiada por la Psicología, que da lugar a la reflexión espontánea de mí mismo: la intencionalidad venida sobre si, como verdad o como ocultamiento en el inconsciente, es para la psicología fenomenológica el centro de la reducción trascendental. En este camino, la epoché en orden a la reducción fenomenológica como reducción trascendental, debe constituirse como una especificidad de la intervención del Psicólogo, especificidad que hasta ahora, apenas y empieza a comprenderse en el ámbito de la ciencia de los fenómenos psíquicos: la psicología.

Wojtyla explica:

Las observaciones en relación con la subconsciencia tienen una importancia especial (...) En primer lugar manifiestan claramente la potencialidad del sujeto dinámico en el mismo aspecto interno. En segundo lugar, nos ayudan a ver, al menos en cierta medida, la continuidad interior y la cohesión del sujeto; (...) En tercer lugar, la subconsciencia, con su relación continúa a la conciencia, nos permite ver al ser humano sometido internamente al tiempo, y, por lo tanto, con su propia historia interna (...) El subconsciente está configurado en gran parte por la conciencia, pero en otro sentido; por lo demás, es únicamente un depósito en que se almacena a la espera de aparecer en la conciencia lo que se contiene en el hombre-sujeto (1982, pág. 113-114). 
Y en el pie de página, aclara que "La afirmación de que el umbral de la conciencia no solo divide, sino que conecta la conciencia y la subconsciencia, solo se puede aceptar en la medida en que las consideremos partiendo de su relación con la potencialidad del hombre" (Wojtyla, 1982, pág. 113).

\section{Conclusión (integración de la persona en la acción)}

El análisis de la autodeterminación nos lleva a la conclusión de que las acciones humanas son resultado del sistema compuesto por autogobierno y autoposesión; este sistema es idéntico y el mismo concepto de "autodeterminación". La acción por otro lado es integración de la persona porque la acción es unidad dinámica superior de la multiplicidad y diversidad de los dinamismos propios de la estructura psico-física: la acción no es suma de dinamismos sino otro dinamismo en el que se integran los demás. La unidad revelada por la acción como integración concluye eidéticamente en el siguiente juicio: una idea correcta del hombre es aquella que lo evidencia como una unidad psicosomática; dice Wojtyla:

El aspecto somático del hombre y el aspecto psíquico están íntimamente interrelacionados, consistiendo la relación entre ellos en el hecho de que las funciones psíquicas están condicionadas por la suma total de las funciones somáticas, y especialmente por algunas funciones somáticas particulares. El término "psique" se refiere a alma, aunque no directamente en sentido metafísico; su primera aplicación es en sentido "físico" o fenoménico. Así, "psique" y "psíquico" se refieren a toda la gama de manifestaciones de la vida integral humana que no son en sí mismas corporales o materiales, pero al mismo tiempo demuestran cierto grado de dependencia del cuerpo, cierto condicionamiento somático (1982, pág. 235).

El alma es el "yo que obra y padece" dice Husserl (1969, pág. 167). "El hombre es su propio yo" dice Wojtyla (1982, pág. 240). El hombre no es el cuerpo, sino que tiene cuerpo: el "Yo" que es la persona tiene cuerpo, pero ese cuerpo no es un sujeto independiente separado del hombre-persona; el cuerpo y el soporte óntico del hombre son una unidad. "Psique" y "soma" en el hombre se funden en una sola estructura. La referencia a "psique" según como la entiende Wojtyla está en correlación con la idea de "soma". El hombre por ejemplo no solo siente su propio cuerpo, sino que tiene una sensación integral de sí, por ejemplo cuando experimenta pasiones o sentimientos, por su capacidad de sentir el hombre se fenomeniza para sí como un ser que no está actuando, sino que algo ocurre en él. Empero la "integración" es una manifestación más pura de la unidad del complejo psico-físico que es, puesto que no se pone como dado solo el dinamismo propio de la persona en acción, sino que se pone como dado también las estructuras y estratos de la complejidad que encarna el ser humano. La acción, la reconstrucción de la experiencia particular del hombre y la actitud fenomenológica son para la intervención clínica del Psicólogo vitales, porque de ellas depende que el concepto conseguido por la intervención psicológica sea eidético.

\section{Bibliografía}

Boss, M. (1979). Existential Foundations of Medicine and Psychology. New York: Jasón Aronson.

Eckhart, Meister. (1978). Deutsche predigten und traktate. München: Carl Hanser.

Henry, Michel. (1963). L'essence de la manifestation. Paris: Presses Universitaires de France.

Hildebrand, Dietrich von. (1976). Was ist Philosophie? Milwuakee: The Bruce Publishing Company
Husserl, Edmund. (1951). La Filosofía como ciencia estricta. Buenos Aires: Universidad de Buenos Aires.

Aires: Nova. (1969). La Filosofía como ciencia estricta. Buenos (1964). Cartesian meditations. The Hague: Martinus Hijhoff. 
Ediciones Paulinas.

(1979). Meditaciones Cartesianas. Madrid: (1982). Investigaciones Lógicas. Madrid: Alianza.

(1991). La crisis de las ciencias europeas y la fenomenología trascendental: una introducción a la filosofía fenomenológica. Barcelona: Crítica.

(1993). Ideas relativas a una fenomenología pura y una filosofía fenomenológica. México: Fondo de cultura económica.

(1995). Ideas relativas a una fenomenología pura y una filosofía fenomenológica. México: Fondo de cultura económica.

(2005). Investigaciones Lógicas. Buenos Aires:

Alianza.

Greening, Tom. (1964). "The Third Force in Psychology". Journal of humanistic Psychology;4(1), 19-25.

Sarte, Jean Paul. (1968). El ser y la nada. Buenos Aires: Losada.

Reeder, Harry P. (2011). La praxis fenomenológica de Husserl. Bogotá: San Pablo.

Rollo, May. (1977). Análisis y significado del movimiento existencial en psicología; y contribuciones de la psicoterapia existencial. Madrid: Gredos.
Schneider, Kirk. (2008). Existential-integrative Psychotherapy. New York: Routledge.

Walton, Roberto. (2008). "Reducción fenomenológica y figuras de la excedencia". Revista de Filosofía de Santa Fe; 16, 169187.

Wojtyla, Karol. (1978). Amor y Responsabilidad. Madrid: Razón y fe.

- (1982). Persona y acción. Madrid: Biblioteca de Autores Cristianos de la Editorial Católica S. A.

.(1998). Mi visión del hombre. Hacia una nueva ética. Madrid: Palabra. 1998.

. (2001). Persona e atto. Milán: Bompiani.

Madrid: Palabra.

. (2003). El don del amor. Escritos sobre la familia.

. (2005). El hombre y su destino. Ensayos de antropología. Madrid: Palabra.

(2011). Persona y acción. Madrid: Palabra.

Revista. Humanismo.Soc. 2013; Volumen 1: 120-132. 